\title{
Pequenas cidades: uma discussão quanto ao aspecto populacional
}

\author{
Small cities: a discussion about the populational aspect \\ Franciele Miranda Ferreira Dias ${ }^{a}$ \\ ${ }^{a}$ Doutora em Geografia pela Universidade Estadual de Londrina (UEL). \\ E-mail: franciele.ferreiradias@gmail.com
}

\begin{abstract}
O objetivo deste trabalho é realizar uma discussão concisa acerca do aspecto populacional como um indicativo daquilo que poderia caracterizar uma pequena cidade, uma vez que, em linhas gerais, o pequeno número populacional está associado ao ideário do que seria uma pequena cidade. Essa discussão surge por haver divergências quanto aos números relativos ao tamanho populacional, sendo que no caso brasileiro eles variam entre 10 mil e 100 mil habitantes. Também há necessidade de distinguir a pequena cidade quanto ao centro local, uma vez que embora guardem aspectos semelhantes, apresentam diferenciações que devem ser explicitadas. Salienta-se que o critério populacional não é o único relevante para a determinação de uma cidade como pequena, pois é necessário entendê-la como parte da rede urbana. Entretanto, através do tamanho populacional é possível buscar o entendimento das relações de produção e circulação de capital, compreendendo assim seu real papel quanto à rede urbana a qual se insere. A metodologia utilizada na elaboração deste artigo pauta-se na consulta bibliográfica quanto à temática escolhida. O artigo é parte dos resultados preliminares da pesquisa de doutoramento em geografia da presente autora.
\end{abstract}

Palavras-chave: pequenas cidades, população, centros locais, metodologia, rede urbana.

The objective of this study is to discuss population as an indicative of what could characterize a small city, since small populations are typically part of the characterization of small cities. This discussion is significant since there are differences as to the numbers employed, and in the Brazilian case, numbers vary between 10 and 100 thousand inhabitants. The need to distinguish small cities from local city centers is also required as they have different characteristics despite their similarities. It should be noted that population is not the only relevant criterion for the determination of a small city, as it has to be understood as part of the urban network. However, by using population size, it is possible to understand the relations of production and circulation of capital, thus understanding its real role in the urban network to which it belongs. The methodology used in this article was bibliography research on the chosen subject. This article is part of the preliminary results of a doctoral research in geography by the present author.

Keywords: small cities, population, city centers, methodology, urban networks. 


\section{INTRODUÇÃO}

As mudanças engendradas pela globalização econômica têm trazido consequências nas cidades em geral e também naquelas que apresentam a menor complexidade econômica e social e população diminuta. Trata-se das pequenas cidades que se tornaram muito heterogêneas quanto à economia que apresentam e, consequentemente, ao papel na divisão territorial do trabalho.

Nesse sentido, embora a temática do estudo das pequenas cidades não seja exclusiva da ciência geográfica, observa-se, no caso do Brasil, um aumento gradativo de estudos, sobretudo nos últimos dois decênios. Apesar disso, o incipiente interesse pelo tema, comparavelmente às cidades de outros tamanhos populacionais, se dá em razão da aparente pouca complexidade que elas apresentam, do ponto de vista econômico e social.

Há inúmeros estudos que tratam de pequenas cidades de forma adjacente, ou seja, abordando alguma problemática que ocorre nesses espaços, não necessariamente relacionada à Geografia Urbana/Econômica. Porém, são poucos estudos que analisam a pequena cidade enquanto um elemento da rede urbana ou mesmo quanto à sua produção no espaço, justamente por aparentarem ser um espaço pouco complexo.

No entanto, o desequilíbrio das redes urbanas em países em desenvolvimento como o Brasil, de acordo com Corrêa (2004), evidencia que essas redes têm poucas cidades médias, havendo preponderância das pequenas cidades; logo, ao serem prevalentes, devem ser estudadas. Também tem sido evidenciado pelo autor citado e por outros que, em virtude das mudanças ocorridas nos últimos decênios quanto à divisão territorial do trabalho, verifica-se que muitas pequenas cidades têm passado por refuncionalizações de suas atividades econômicas e, em alguns casos, surgem as denominadas especializações funcionais. Assim, com a complexidade econômica e social, adquirida por algumas pequenas cidades, faz-se válido o estudo destas.

Embora as pequenas cidades sejam prevalentes no Brasil, sua quantidade aumentou gradativamente durante o século XX, coincidindo com o processo de urbanização brasileira. Também, com a promulgação da Constituição Federal de 1988, evidencia-se que aumentaram gradativamente com a emancipação ${ }^{1}$

1 Tomio (2002) faz uma análise pormenorizada da criação e emancipação de municípios brasileiros no período após a promulgação da Constituição Federal de 1988. de inúmeros núcleos urbanos em maioria diminutos. Logo, intensifica-se o questionamento do que é rural e o que é urbano e, por conseguinte, o fator populacional mostra-se novamente relevante.

Por outro lado, revela-se bastante intrincada a definição do que seria uma cidade, em especial em um país com dimensões continentais como o Brasil, onde se têm cidades com populações bastante heterogêneas, diferenças econômicas e sociais resultantes do processo de urbanização que se deu diferentemente no contexto nacional. Quanto à definição do que seria uma pequena cidade, o consenso também não existe e não há ainda uma metodologia concretizada no que tange a seu estudo. Por essa razão, nota-se que se sobressaem duas hipotéticas opções metodológicas, ou seja, o viés quantitativo, ou demográfico, e aquele de cunho qualitativo, no qual a pequena cidade é analisada quanto à influência da formação socioespacial, a inserção na rede urbana, entre outros elementos.

Embora consideremos acertado os estudos que se pautam na análise constituída principalmente pela opção metodológica qualitativa, o aspecto quantitativo é importante sobretudo quanto à definição prévia do que seria uma pequena cidade. Isso porque se deve buscar a compreensão quanto ao tamanho populacional mínimo que caracteriza uma pequena cidade, e também qual o tamanho máximo que pode apresentar a fim de que não se configure como uma cidade média. $\mathrm{O}$ fator populacional não se mostra unicamente determinante para a definição daquilo que seria uma pequena cidade, sendo esse aspecto discutido no presente artigo.

Apesar disso, entendemos ser conveniente uma breve discussão teórica sobre o que seria a pequena cidade, sobre o ponto de vista populacional, uma vez que há uma diversidade enorme de apontamentos numéricos utilizados para tal classificação. Também, de forma geral, pode-se entender que uma cidade é pequena devido ao seu tamanho territorial e populacional. Por essa razão, embora não seja unicamente suficiente para delimitarmos o que é uma pequena cidade, esse critério mostra-se como um indicativo.

Salienta-se que a discussão presente neste artigo se refere ao Brasil, quanto à delimitação da área de estudo, e apresenta como recorte temporal o final do século XX e início do XXI. Deve-se entender, portanto, que a denominação do que seria uma cidade, mediante seu tamanho populacional, mostra-se como uma questão bastante discutível quanto a outros países, uma vez que os critérios demográficos e/ou administrativos são 
bastante heterogêneos. Há ainda a questão do tempo, ou seja, em cada período histórico, o significado do que é uma cidade e o respectivo tamanho que a caracteriza como pequena, média ou grande, alteram-se. Por conseguinte, de acordo com Lencione (2008), considera-se o tempo histórico porque um aglomerado urbano pode ser avaliado como cidade em um período e em outro não, uma vez que o tamanho das cidades tem significados diferentes em realidades distintas.

O presente artigo é parte dos resultados da pesquisa de doutoramento da autora. Esclarecemos que compartilhamos dos pressupostos teóricos da professora Tania Fresca (1993, 2010), segundo os quais a pequena cidade só pode ser compreendida de fato através da concepção de sua inserção na rede urbana, e também acreditamos nos pressupostos teóricos do professor Milton Santos (1982, 2005) quanto às diferenças existentes entre as pequenas cidades e as cidades locais, como um aspecto relevante na compreensão do que é uma pequena cidade.

A metodologia utilizada no presente trabalho consiste na consulta bibliográfica acerca do tema pequenas cidades, destacando-se os autores Santos (1982, 2005), Fresca (2010), Corrêa (1999, 2004) e Endlich (2009) por fundamentarem teoricamente os aspectos primordiais ao entendimento da temática supracitada. Também foram consultados artigos científicos no âmbito da Geografia relativos às pequenas cidades, a fim de avaliar qual o patamar demográfico considerado pelos diversos autores a fim de caracterizar uma pequena cidade. Salienta-se que não se tem o objetivo de esgotar tal avaliação, pois a bibliografia referente ao tema, embora ainda seja diminuta se comparada aos demais tamanhos de cidade, têm aumentado gradativamente e, portanto, exige uma pesquisa de outra magnitude.

\section{REDE URBANA E PEQUENA CIDADE}

Primeiramente, devemos considerar a importância da teoria das localidades centrais de Christaller (1966) ${ }^{2}$, uma vez que, ao avaliar os papéis que os centros urbanos poderiam desempenhar na denominada rede urbana, traz

2 A teoria citada procurava estabelecer o entendimento de uma rede urbana no sul da Alemanha em 1933, considerando para tal o estudo das funções que os núcleos urbanos apresentavam. Essas análises consideravam que as cidades se tornavam grandes e importantes mediante fatores aleatórios e também devido à proximidade com a metrópole. à tona o fato de que a pequena cidade existe e, como tal, deve ser considerada nos estudos sobre o urbano. Muito embora incialmente a pequena cidade não fosse objeto de estudo frequente, é necessário entender o papel que tais núcleos urbanos desempenham a fim de compreender a rede urbana em sua totalidade.

Apesar de a teoria das localidades centrais se tratar de um estudo no qual a rede urbana e a importância hierárquica dos centros urbanos fossem determinadas por métodos quantitativos, sem a discussão dos aspectos econômicos e sociais, surge, a partir de então, a necessidade de olhar para as demais cidades da rede urbana, embora tal colocação fosse de fato desenvolvida apenas no último quartel do século XX. No Brasil, as pesquisas que abarcam o tema pequenas cidades tornaram-se gradativamente recorrentes nos últimos dois decênios, embora ainda sejam pouco numerosas em comparação aos estudos acerca das cidades médias, grandes e metrópoles.

No entanto, há alguns esforços temporalmente anteriores com o objetivo de compreender o significado das pequenas cidades quanto a sua gênese e seu papel na rede urbana. Entre eles, Geiger (1963) procurou compreender como surgiram as cidades brasileiras, pensando em uma elementar rede urbana. Embora não tenha discutido propriamente o tamanho das cidades, atrelou sua análise às funções que elas apresentavam, analisando assim o que se poderia considerar funcionalmente como uma cidade. Posteriormente, Berry (1975) atribuiu o tamanho e distribuição das cidades ao respectivo desenvolvimento econômico, com isso, a cidade primaz era aquela na qual se concentravam os serviços e produtos mais específicos. Também o crescimento econômico estaria relacionado à distância que a cidade apresenta da metrópole, portanto, aquelas mais distantes seriam menores e, deste modo, menos desenvolvidas e caracterizadas por baixa renda.

No entanto, cabe pontuar que o método empregado até então quanto ao estudo da rede de cidades considerava a localização como resultado da combinação de variáveis relativas à produção e ao escoamento, bem como custos de transportes. Assim, as cidades dos mais diferentes portes eram estudadas quanto à rede urbana, porém se apresentando como itens de um sistema, no qual os elementos eram analisados de forma meramente quantitativa.

É importante destacarmos os estudos realizados pelo Instituto Brasileiro de Geografia e Estatística (IBGE, 1966, 1978, 1993, 2007), denominados Região de influência das cidades (Regic), que apontaram que há no Brasil uma hierarquia urbana, sendo a pequena cidade o nível mais elementar de núcleo urbano. Essa hierarquia, no entanto, 
tem demonstrado que as pequenas cidades podem exercer funções bastante diferentes na rede urbana e, consequentemente, na divisão territorial do trabalho, levando em parte ao interesse pelo estudo destas. Cabe pontuar que os Regics, de forma geral, apresentam lacunas a serem abordadas, uma vez que não abrangem todas as especificidades nas relações entre os núcleos urbanos e, portanto, apresentam a possibilidade de estudos acadêmicos voltados a essa questão.

Entretanto, muitos estudos foram realizados após os primeiros Regics com o intuito de compreender o papel que os diferentes patamares de cidade exerciam na rede urbana. A partir da abordagem teórica de cunho marxista, oriunda da Geografia Crítica, que se tornou predominante nos últimos decênios do século XX, têm-se o estudo das cidades não apenas como meros pontos da rede urbana, pois esta passa a ser entendida como a materialização da divisão territorial do trabalho. Portanto, autores como Corrêa (2004) e Fresca (1993) desenvolveram uma extensa análise teórica quanto ao papel das pequenas cidades na rede urbana, evidenciando que não se pode pensar apenas em um sistema simples de variáveis, uma vez que se mostram determinantes, entre outros fatores, os desdobramentos da globalização econômica que certamente atingem a pequena cidade.

\section{Pequenas CIDAdes: A DisCUssão QUANTO AO ASPECTO POPULACIONAL}

O advento da denominada Geografia Crítica durante as últimas décadas do século XX alterou o enfoque quanto ao estudo das redes urbanas e também das pequenas cidades. A discussão deixa de atrelar-se apenas a modelos e sistemas aleatórios, que não consideravam as mudanças na divisão territorial de trabalho e, por consequência, da globalização. Nessa perspectiva, a Geografia Urbana atual busca identificar as pequenas cidades e analisá-las no contexto da globalização econômica e seus desdobramentos.

Assim, o aspecto populacional surge na perspectiva de compreender uma das supostas características dessas cidades, sendo o ideário da população diminuta presente não apenas no contexto acadêmico, mas também no senso comum. Entretanto, o fator populacional é muito divergente, não existindo consenso, o que torna primordial estabelecer qual o limite populacional mínimo e máximo daquilo que se pode considerar como pequena cidade.
Inicialmente, ao discutir, no âmbito da Geografia Urbana, questões relativas às cidades, deve-se ponderar a diferença quanto ao município, a fim de balizar o objeto de estudo. Nesse sentido, as cidades no Brasil, via de regra, são as sedes administrativas de cada município, importantes principalmente ao pensar a rede urbana enquanto um recorte geográfico, pois se atrela ao papel que as cidades desempenham, considerando seus fluxos populacionais, interações econômicas, produção de bens e serviços, entre outros. O município abrange tanto a sede administrativa, portanto, a cidade, quanto a área rural ao seu entorno, concluindo-se que ambos reunidos evidenciam o que se determina como município.

O Brasil é um país majoritariamente urbano, com 84,36\% da população habitando cidades (IBGE, 2010). Para o IBGE, predominam as pequenas cidades, ou seja, aquelas que apresentam população de até 50 mil habitantes, não existindo número mínimo que as caracterize. No entanto, os números usados pelo Instituto quanto ao tamanho populacional das pequenas cidades referem-se ao período hodierno e servem para direcionar as pesquisas de diversos órgãos brasileiros. Embora de modo geral os autores considerem tais números, é sabido que não é possível compreender a realidade meramente por tal aspecto. Isso porque, de acordo com Fresca (2010), uma pequena cidade só poderá ser compreendida se considerarmos o papel que exerce em sua respectiva rede urbana.

Outro indicativo para o tamanho populacional relativo à pequena cidade é oriundo do Instituto de Pesquisa Econômica Aplicada (Ipea) (2000), para o qual as pequenas cidades apresentam menos de 50 mil habitantes. Especificamente, para o Ipea, as pequenas cidades se subdividem em três grupos por tamanho populacional, sendo o primeiro grupo de até 10 mil habitantes, o segundo, de 10 a 20 mil habitantes, e o terceiro de 20 a 50 mil habitantes.

Entretanto, nem todos os autores seguem os números estipulados pelo IBGE e pelo Ipea. Entre eles, Amorim Filho e Serra (2001) consideram o número inferior a 100 mil habitantes caracterizado como pequena cidade, e entre 100 e 500 mil habitantes caracterizaria as cidades médias. Lopes (2009) e Veiga (2002) acreditam que uma pequena cidade não ultrapassa o tamanho populacional de 20 mil habitantes, enquanto Oliveira e Soares (2002), em sua análise sobre o papel desempenhado pelas pequenas cidades no triângulo mineiro, consideram a população entre 2 e 20 mil habitantes como relativas às pequenas cidades. 
Para Wanderley (2011), os pequenos municípios seriam aqueles que reúnem população inferior a 20 mil habitantes, evidenciando uma confusão entre o que é cidade e o que é município. Assim, as pequenas cidades estariam atreladas ao "mundo rural", dos pequenos municípios, considerando que a população rural seria necessariamente predominante, o que obviamente nos parece contestável, uma vez que o IBGE aponta que a maioria dos municípios brasileiros apresenta altas taxas de urbanização.

Para alguns autores, o critério populacional mostra-se suficiente para caracterizar uma pequena cidade. Entre estes estão Assis et al. (2007), para os quais a população inferior a 100 mil habitantes caracteriza uma pequena cidade. Para os autores, o fator populacional seria um indicativo aceitável para compreender uma cidade como pequena, não discutindo suas funções na rede urbana bem como a complexidade econômica que apresentam.

De acordo com Santos (1982), o aspecto populacional não deve ser o único válido para o estudo das pequenas cidades, devido à importância de se compreender a dinâmica das necessidades das populações atreladas a uma especialização que as cidades podem desenvolver. Endlich (2006) também evidencia que o fator populacional é incompleto para identificar uma cidade como pequena, apontando que podem existir inclusive relações hierárquicas entre esses pequenos núcleos urbanos.

Fresca (2010) compreende que, no que tange às pequenas cidades, podem encontrar-se aquelas com um limite mínimo de complexidade nas atividades urbanas e mesmo aquelas com funções urbanas muito complexas. Portanto, para caracterizar uma cidade como pequena é preciso entender sua inserção na rede urbana ou região no contexto socioeconômico, a fim de não igualar cidades com populações análogas que apresentam características sociais e econômicas diferentes. Isto é, deve-se desviar da generalização populacional e também do ideário de que as pequenas cidades teriam como função apenas fornecer bens e serviços básicos à população em dado espaço restrito.

Corrêa (2001) argumenta que a pequena cidade, ou pequeno centro, pode ser mais bem definida em termos do grau de centralidade do que em relação ao tamanho demográfico. $\mathrm{O}$ autor considera a pequena cidade como um núcleo de povoamento onde parte da população trabalha em atividades ligadas à transformação, circulação de mercadorias e prestação de serviços, apresentando até 50 mil habitantes. De tal forma, o autor pressupõe que a pequena cidade apresenta uma elementar divisão territorial do trabalho e que, portanto, não pode ser estudada de forma dissociada da rede urbana.

\section{Cidades lOCAIS: UMA BREVE REFLEXÃO DO SIGNIFICADO TEÓRICO}

De acordo com Santos (1982), a maioria dos estudos urbanos em países subdesenvolvidos estavam atrelados às grandes metrópoles, sobretudo ao fenômeno da macrocefalia urbana, inexistindo a preocupação com a compreensão da pequena cidade. Em realidade, o autor entendia que as pequenas cidades eram percebidas somente quanto ao aspecto numérico, ou seja, em relação à quantidade de moradores que as habitavam, logo, não sendo avaliadas quanto às funções que apresentavam.

Assim, o autor preocupou-se mormente com o aspecto qualitativo da análise das pequenas cidades, diferenciando pequena cidade de cidade local (SANTOS, 1982). Para tal, criou uma hierarquia urbana na qual constavam as cidades locais, cidades regionais, metrópoles incompletas e metrópoles completas. A hierarquia explicitada apresentava tendência piramidal, na qual, em busca de determinados bens e serviços, as cidades recorreriam àquelas que apresentassem níveis hierárquicos superiores. Nessa perspectiva, as cidades locais seriam os núcleos menos complexos do ponto de vista funcional.

Dessa maneira, as cidades locais seriam aqueles núcleos urbanos destinados apenas a atender a demandas mínimas, enquanto as pequenas cidades poderiam desempenhar atividades que sobrepõem o local, no caso, por exemplo, das especializações funcionais, tratadas, entre outros autores, por Veiga (2007). Portanto, a cidade local de Milton Santos (1982) reflete aquele ambiente urbano que atende apenas a demandas mínimas, enquanto a pequena cidade pode apresentar uma grande gama de variedades quanto a sua composição social e econômica, podendo ser mais ou menos complexa do ponto de vista funcional na rede urbana. De tal modo, surgem discussões que interrogam o que de fato é uma cidade local, considerando se a cidade apresenta uma complexidade mínima ${ }^{3}$, oriunda da divisão territorial do trabalho.

3 Outro fato importante exposto pelo autor citado (SANTOS, 1982) é a falta de complexidade mínima de atividades que algumas cidades apresentam, as quais poderiam ser denominadas, segundo o autor, como pseudocidades, não atrelando apenas ao fator populacional. Porém, por ser uma temática bastante restritiva, caberia uma pesquisa direcionada a tal conotação conceitual. 
Acerca desse aspecto apontado por Santos (1982), Endlich (2009) apontou a relevância do estudo dos núcleos urbanos diminutos, aqueles que se encontram no limiar entre o rural e o urbano, uma vez que tais cidades não apresentam, em geral, equipamentos que atendam às necessidades mínimas da população. Tais núcleos urbanos, embora possam ser considerados como centros locais, também são pequenas cidades e, portanto, cabe a reflexão quanto ao limiar entre o que é rural e urbano, outro aspecto bastante caro para aqueles pesquisadores que se dedicam ao estudo das pequenas cidades.

\section{Conclusão}

No Brasil, a Geografia não apresentou incialmente estudos que abarcassem as pequenas cidades quanto à discussão de seu papel na rede urbana e suas funcionalidades. $\mathrm{O}$ crescente interesse pela compreensão desse tipo de cidade data do último quartel do século XX, sendo resultante da complexificação do processo de acumulação capitalista e seus desdobramentos, revelados nas mudanças na divisão territorial do trabalho.

A discussão acerca do porte populacional que as pequenas cidades apresentam, quanto ao limiar mínimo e máximo, expõe divergências, uma vez que a discussão teórica sobre esse tipo de cidade ainda é recente, e o aporte metodológico para seu estudo se encontra em discussão. Por outro lado, o aspecto populacional não é um critério exclusivo para a definição de uma pequena cidade, embora seja um indicativo, já que a pequena cidade é, em realidade, uma pequena sede municipal com população diminuta e tamanho territorial pequeno.

Entende-se que apenas o critério populacional é incompleto para compreender o que é uma pequena cidade, porém é um dos aspectos consideráveis nessa questão, e por isso se fundamentou a presente discussão. Em realidade, o porte demográfico de uma cidade é considerado por muitos estudiosos o ponto de partida para estudá-la.

Ao consultar artigos e demais trabalhos acadêmicos que versam sobre a pequena cidade, observaram-se números variáveis para a compreensão do que é uma pequena cidade. De maneira geral, os autores seguem o estipulado pelo IBGE, sendo o máximo de 50 mil habitantes, embora existam casos bastante discordantes. Consideramos importante não apenas estabelecer o tamanho populacional da pequena cidade, mas também entendê-la como um elemento da rede urbana, uma vez que cidades com o mesmo tamanho demográfico podem apresentar papeis diferentes no caso de redes urbanas distintas.

Parece-nos, dessa maneira, plausível considerar como pequena cidade aquelas que apresentam populações de até 50 mil habitantes e, ao pensar em tais números, concluiremos que a maioria das cidades brasileiras se enquadram nessa categoria. Destarte, mostram-se imprescindíveis estudos que abarquem as pequenas cidades, uma vez que são parte da rede urbana e necessárias para sua compreensão completa.

\section{REFERÊNCIAS}

AMORIM FILHO, O.; SERRA, R. V. Evolução e perspectivas do papel das cidades médias no planejamento urbano e regional. In: ANDRADE, T. A.; SERRA, R. V. (org.). Cidades médias brasileiras. Rio de Janeiro: Ipea, 2001. p. 1-34.

ASSIS, L. F.; ARAÚJO, F. F.; GOMES, M. F. A terceirização na cidade média de Sobral e suas influências nas cidades pequenas de Cariré e Varjota - CE. Revista da Casa da Geografia de Sobral, Sobral, v. 8-9, n. 1, p. 123-140, 2007.

BERRY, B. Geografia de los centros de mercado y distribuição al por menor. Barcelona: Vicens Vivers, 1971.

CHRISTALLER, W. Central places in Southern Germany. Prentice-Hall: Englewood Cliffs, 1966.

GORRÊA, R. L. Globalização e reestruturação da rede urbana: uma nota sobre as pequenas cidades. Território, Rio de Janeiro, v. 6, n. 6, p. 43-53, 1999.

CORRÊA, R. L Rede urbana: reflexões, hipóteses e questionamentos sobre um tema negligenciado. Cidades, Presidente Prudente, v. 1, n. 1, p. 65-78. jan./jun. 2004.

\section{ENDLICH, Â. M. Pensando os papéis e significa-} dos das pequenas cidades. 2006. Tese (Doutorado em Geografia) - Faculdade de Ciências e Tecnologia, Universidade Estadual Paulista, Presidente Prudente, 2006. 
ENDLICH, Â. M.; ROCHA, M. M. (org.). Pequenas cidades e desenvolvimento local. Maringá: PGE, 2009.

FRESCA, T. O papel das pequenas cidades na rede urbana do Oeste Paulista. In: ENGUENTRO DE GEÓGRAFOS DE AMERICA LATINA, 4., 1993, Merida. Anais [...]. Merida: Faculdade de Los Andes, 1993. p. 181-190.

FRESCA, T. Centros locais e pequenas cidades: diferenças necessárias. Revista Mercator, Fortaleza, n. esp., p. 75-81, 2010.

GEIGER, P. P. Evolução da rede urbana brasileira. Rio de Janeiro: Instituto Nacional de Estudos Pedagógicos, 1963.

IBGE - INSTITUTO BRASILEIRO DE GEOGRAFIA E ESTATÍSTICA. Regiões de influência de cidades: 1966. Rio de Janeiro: IBGE, 1972.

IBGE - INSTITUTO BRASILEIRO DE GEOGRAFIA E ESTATÍSTICA. Regiões de influência de cidades: 1973. Rio de Janeiro: IBGE, 1987.

IBGE - INSTITUTO BRASILEIRO DE GEOGRAFIA E ESTATÍSTICA. Regiões de influência de cidades: 1993. Rio de Janeiro: IBGE, 2000.

IBGE - INSTITUTO BRASILEIRO DE GEOGRAFIA E ESTATÍSTICA. Regiões de influência de cidades: 2007. Rio de Janeiro: IBGE, 2008.

\section{IPEA - INSTITUTO DE PESQUISAS} ECONÔMICAS APLICADA. Garacterização e Tendências da Rede Urbana no Brasil. Brasília, DF: IPEA; Rio de Janeiro: IBGE; Campinas: Unicamp, 2000. (Coleção Pesquisa 3v.).
LENCIONE, S. Observações sobre o conceito de cidade e urbano. GEOUSP, São Paulo, v. 12, n. 1, p. 109-123, 2008.

LOPES, D. M. F. Cidades: conceitos, processos e história. Bahia Análise \& Dados, Salvador, v. 19, n. 2, p. 395-412, jul./set. 2009.

OLIVEIRA, B. S.; SOARES, B. R. Cidades locais do triângulo mineiro e Alto Parnaíba/MG. Caminhos da Geografia, Uberlândia, v. 3, n. 5, p. 52-72, 2002.

SANTOS, M. Espaço e sociedade. Petrópolis: Vozes, 1982.

SOARES, B. B. Pequenas e médias cidades: um estudo sobre as relações socioespaciais nas áreas de cerrado em Minas Gerais-MG. In: SPÓSITO, M. E. B. (org.). Gidades médias: espaços de transição. São Paulo: Expressão Popular, 2007. p. 461-494.

TOMIO, F. R. L. A criação de municípios após a Constituição de 1988. Revista Brasileira de Giências Sociais, São Paulo, v. 17, n. 48, p. 61-89, 2002.

VEIGA, J. E. Gidades imaginárias: o Brasil é menos urbano do que se calcula. São Paulo: Edusp, 2002.

VEIGA, L. A. Jaguapitã-PR: pequena cidade da rede urbana norte-paranaense especializada na produção industrial de mesas de bilhar. 2007. Dissertação (Mestrado em Geografia) - Centro de Ciências Exatas, Universidade Estadual de Londrina, Londrina, 2007.

WANDERLEY, M. N. B. Urbanização e ruralidade: relações entre a pequena cidade e o mundo rural: estudo preliminar sobre os pequenos municípios em Pernambuco.

Revista Nordeste: regionalismo e inserção global, Heredia, v. 1, n. 1, p. 05-32, 2001. Disponível em: http://bit.ly/39qLJVM. Acesso em: 1 ago. 2017. 